\title{
A GSM Based Assistive Device for Blind, Deaf and Dumb
}

\author{
Lavanya Dhanesh ${ }^{\mathrm{a}, 1}$, Monica $\mathrm{S}{ }^{\mathrm{b}}$, Revathi $\mathrm{R}^{\mathrm{b}}$, Suganya $\mathrm{S}{ }^{\mathrm{b}}$, Swetha lakshmi K $\mathrm{N}^{\mathrm{b}}$ \\ ${ }^{a}$ Associate Professor, ${ }^{b} U G$ Student, Department of Electrical and Electronics \\ Engineering, Panimalar Institute of Technology, Chennai, TN, India
}

\begin{abstract}
This paper tries to overcome the shortcomings of the recent technology that fails to enhance the communication between physically disabled people by designing an assistive device. This device uses a GSM modem with a SIM card and no smartphones are needed which makes the device affordable. Here, the sender sends the message to the phone number of the disabled person and he/she receives the SMS that gets converted to text and voice message and vibrations to Braille pad using a microcontroller which is easily readable by the disabled person.
\end{abstract}

Keywords. GSM modem, text and voice message, microcontroller

\section{Introduction}

In today's world, digital technologies play a major role in communication by bridging people anytime and anywhere across the world. Digital technology includes mobile phones, e-mails, the internet, social media, etc., which makes communication between normal people simpler [1]. But the physically impaired people particularly blind, deaf and dumb are lacking the ease of using modern technology. Around 285 million individuals are encountered to be visually disabled worldwide of which 39 million are visually impaired and 246 are said to have low vision and about 9.1 billion individuals have a hearing defect and are dumb. Despite the advancements in technology, a device that comprises all the necessities for better communication between the three categories of disabled people mentioned above is still lacking a proper structure of communication [2-4]. Hence, we have designed a device that makes communication easier and affordable for disabled people. This device mainly focuses on SMS technology using GSM [5-6]. Global System for Mobile communication is abbreviated as GSM and it is used with mobile phones as a digital mobile network.

The output of this device is in the form of braille language, text message, and voice message which is useful to the blind, deaf and dumb respectively. Braille is a tangible reading and writing system used by visually disabled people [7-9]. It is generally written on imposed paper. Braille was created by Louis Braille. Braille pad contains several cells and each cell has six elevated dots which is used to represent various characters. The arrangement and number of these dots represent different characters, numbers, and symbols. On the other hand, an LCD and the speaker convey the text and voice message to deaf and dumb people.

\footnotetext{
${ }^{1}$ Lavanya Dhanesh, Department of Electrical and Electronics Engineering, Panimalar Institute of Technology, Chennai, TN, India; Email: lavanyadhanesh2007@gmail.com.
} 


\section{Literature Review}

Choudhary Tanay, Kulkarni Saurabh, Reddy Pradyumna; 16 April 2015; “A Braillebased mobile communication and translation glove for deaf-blind people", This paper is a novel methodology for the interaction between blind individuals independently. The paper defines the use of a Bluetooth device connected to a phone while a lowpower microcontroller unit is used in it [1].

Banmare Amar, Chawhan S Ashika, Lanjewar R. Aditi, Nikhade R. Karishma, Siriya P. Meghna; March 2018; "Hardware Based Braille Pad on Mobile Phone", This paper proposes an aim to provide a Microcontroller-based Braille Pad system that provides information to blind people by using Global System for Mobile Communications (GSM), helping the visually disabled to communicate. The details of simulation in Proteus 8 professional software and embedded module have been furnished in this paper [2].

Shraddha R. Ghorpade, Surendra K. Waghamare; 2015; "Full Duplex Communication System for Deaf \& Dumb People",This paper proposes a system that converts ordinary person's speech to text and displays the corresponding gesture on the display. In this way, the entire thought is to assemble a gadget that empowers two-route communication between a disabled individual and a typical individual [3].

Suharjito, Ricky Anderson, Fanny Wiryana, Meita Chandra Ariesta, Gede Putra Kusuma; October 2017; "Sign Language Recognition Application Systems for DeafMute People: A Review Based on Input-Process-Output", This paper surveys different communication via gestures acknowledgment approaches and assists the researcher with tracking down the best methodology among them to develop better Sign Language Application Systems later on [4].

Brian Frey, Caleb Southern, Mario Romero; "Mobile Texting for the Visually Impaired" This paper focuses on IOS technology. The iPod model incorporates a plan that helps the user hold the device and position the fingers on the keys. Users hold Braille Touch by both hands and use their fingers in a layout with a one-to-one correspondence to Braille writer [5].

\section{Need for the Study}

Even though the advancements in the technologies invented many devices for the disabled people, they someway include the usage of smartphones which makes it less affordable. So, there is a need for a device that is more affordable and simpler [10].

\section{Proposed System}

The proposed system tries to overcome the difficulties by introducing a device that uses no smartphones and makes communication simple with SMS technology. He3re, the sender sends the message to the phone number of the disabled person and he/she receives the SMS that gets converted to text and voice message and vibrations in the Braille pad using a microcontroller. Signals will be sent to the device which will contain vibration motors attached to the Braille dots. The SIM card is kept in a slot through which the text input goes to the microcontroller and a program in 
microcontroller then converts the text into Braille characters, voice message and also displayed in text format.

\section{System Design}

The system contains a GSM modem, Arduino board, ATmega microcontroller, relays, braille pad, speaker, and LCD Display. SMS is received by the GSM modem. Serial Communication Transmission Port (RS-232) is used to communicate between Microcontroller and GSM. SMS goes through a set of code where Microcontroller receives the SMS and vibrates the vibration motors based on text received which is attached to Braille Pad. Also, the microcontroller converts the SMS into a voice message and displays the text in LCD [11-12]. GSM means Global System for Mobile communication. It is a digital mobile telephone communication system. By the Advance GSM module interface in our proposed system, we send short instant messages to particular authorized users according to the application. GSM module is furnished with a SIM that utilizes the mobile service provider and sends SMS to the respective user according to programmed. This is a plug-and-play GSM Modem that is simpler to execute RS232 and TTL serial interface. It is used to send SMS, settle on and get decisions, and do other GSM activities by basic AT orders through a sequential interface from microcontrollers and PCs. The Arduinos are worked around an ATmega microcontroller, where the program of our proposed system is being uploaded and compiles the code written in Embedded " $\mathrm{C}$ " to the board. The relay is used to control different devices by turning on and off them whenever necessary. Here, six relays are used for six braille dots. Since the relays have jumpers no voltage regulators are needed and the direct power supply can be given to the relays [13-15]. The Braille pad is employed in our proposed system. It has tiny bumps called raised dots are present which is represented as a braille cell. The number and arrangement of these dots represent different characters, numbers, and symbols. A Braille cell contains six raised dots arranged in two parallel columns each having three dots. The dot positions are recognized by numbers from one to six. There is a Liquid Crystal Display interfaced with the microcontroller to verify the output of our proposed system.

\section{Results and Discussions}

The Figure 1 signifies the Prototype model of our proposed system. The Braille cell is shown in the Figure 2 and the Braille Reference Chart is shown in the Figure 3. The Braille Reference Chart, maps each cell of the Braille to an ASCII character The ASCII Braille refers to the codes which have to be sent to a Braille Embosser, to correctly print the cells corresponding to the text to be transcribed. 


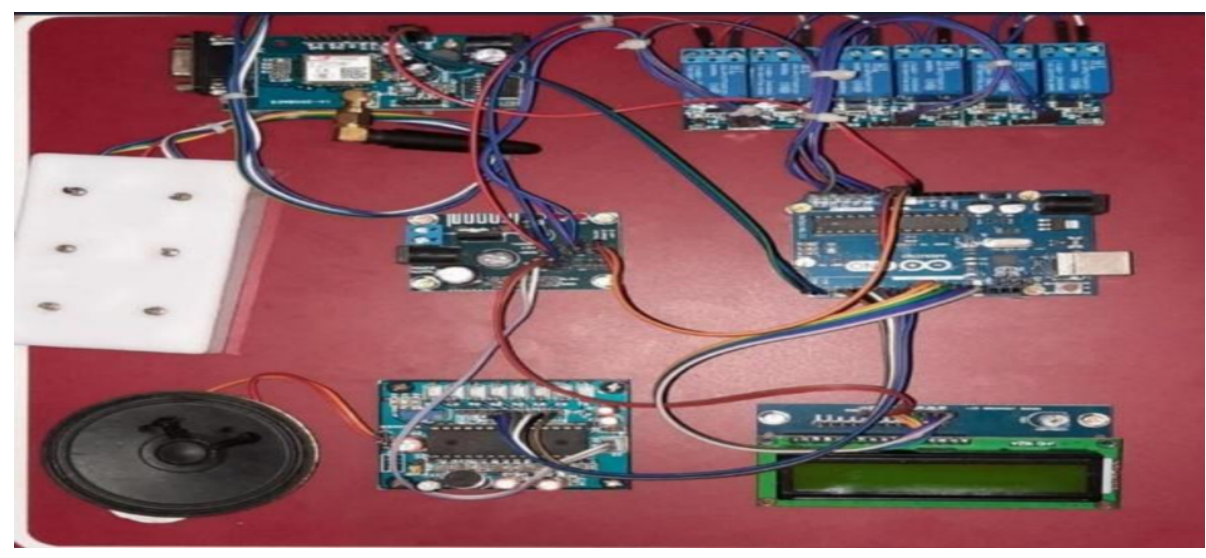

Figure 1. Prototype Model of Our Proposed System

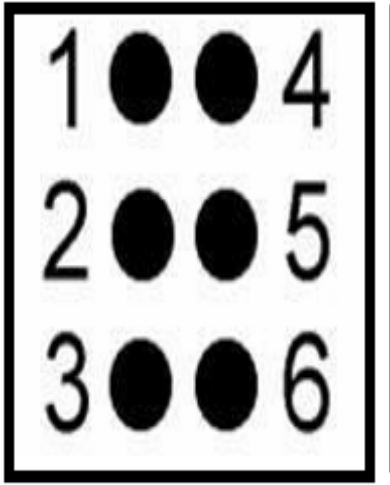

Figure 2. The Braille Cell

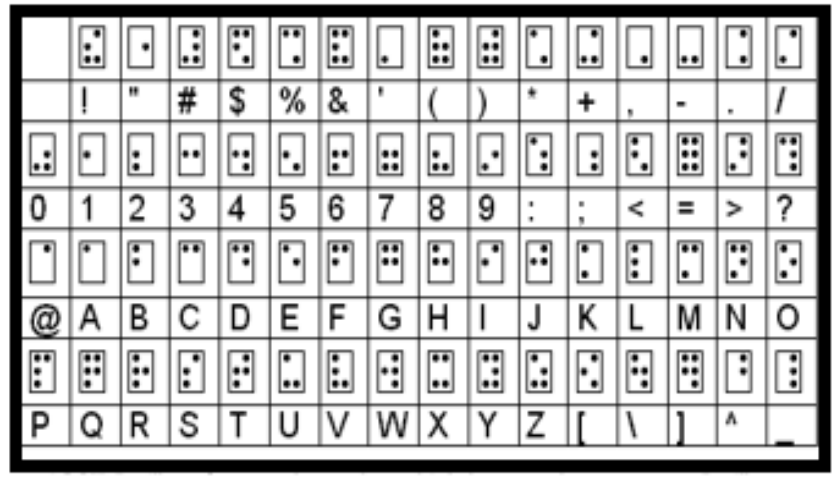

Figure 3. The Braille Reference Chart

\section{Conclusion}

In this paper, the proposed device aids disabled people to communicate more simply. The primary objective of this device is to provide an affordable and easily portable mode of communication. This model is a solitary smaller gadget exclusively for the blind, deaf, and dumb people. The primary factor of this model is to work with these individuals and to make them more certain to work autonomously.

\section{References}

[1] Miele, J.A., Weara Braille: development of a wireless, virtual, Braille keyboard, in 25th Annu. Int.Technology \& Persons with Disabilities Conf. (2010)

[2] Caporusso, N. (2008). A wearable malossi alphabet interface for deafblind people]. In Proceedings of the Workshop on Advanced Visual Interfaces AVI (pp. 445-446). https://doi.org/10.1145/ 1385569.1385655 
[3] Assistive Technology for the Hearing-impaired, Deaf and Deafblind. (2003). Assistive Technology for the Hearing-impaired, Deaf and Deafblind. Springer-Verlag. https://doi.org/10.1007/b97528

[4] Braille Touch: Mobile Texting for the Visually Impaired, Brian Frey, Caleb Southern, Mario Romero: Advance SMS System for Blind Peoples using Braille Pad, Harshal A Dahake and Sunil U Nyati Shraddha R. Ghorpade, Surendra K. Waghamare, "Full DuplexCommunication System for Deaf \& Dumb People," International Journal of Emerging Technology and Advanced Engineering (IJETAE), Volume 5, Issue 5, May 2015, ISSN 2250-2459.

[5] Er. Aditi Kalsh, Dr. N.S. Garewal, "Sign Language Recognition System," International Journal of Computational Engineering Research (IJCER), Volume 03, Issue 6, June 2013.

[6] Bhame, V., Sreemathy, R., \& Dhumal, H. (2014). Vision based hand gesture recognition using eccentric approach for human computer interaction. In Proceedings of the 2014 International Conference on Advances in Computing, Communications and Informatics, ICACCI 2014 (pp. 949953). Institute of Electrical and Electronics Engineers Inc. https://doi.org/10.1109/ ICACCI.2014.6968545

[7] Schmid, C., Mohr, R., \& Bauckhage, C. (2000). Evaluation of interest point detectors. International Journal of Computer Vision, 37(2), 151-172. https://doi.org/10.1023/A:1008199403446

[8] Dhanesh, L. (2018). Automated Intimation to Ambulance for Emergency Medical Service and Traffic Clearance Using Internet of Things (Iot). International Journal for Research in Applied Science and Engineering Technology, 6(3), 2829-2834. https://doi.org/10.22214/ijraset.2018.3455

[9] Dr.Lavanya Dhanesh , "An Smart Load Management System For Homes Using IOT", in the International Journal of Advance Research in Engineering, Science \& Technology, e-ISSN: 2393-9877, Volume: 5, Issue: 3, Mar-2018.

[10] Dhanesh, L., \& Murugesan, P. (2017). Smart scheduling of the real-time tasks using the cyclic priority preemptive pipeline scheduling algorithm. Journal of Computational and Theoretical Nanoscience, 14(4), 1813-1820. https://doi.org/10.1166/jctn.2017.6510

[11] Dhanesh, L., Deepa, S., Elangovan, P., \& Prabhu, S. (2020). Enhanced and Energy-Efficient Program Scheduling for Heterogeneous Multi-Core Processors System. In Lecture Notes in Electrical Engineering (Vol. 665, pp. 737-747). Springer. https://doi.org/10.1007/978-981-15-5262-5_55

[12] Dhanesh, L., \& Murugesan, P. (2018). A novel approach in scheduling of the real- time tasks in heterogeneous multicore processor with fuzzy logic technique for micro-grid power management. International Journal of Power Electronics and Drive Systems, 9(1), 80-88. https://doi.org/10.11591/ijpeds.v9n1.pp80-88

[13] Dr.Lavanya Dhanesh , "Implementation of IOT Based Self Learning Home Energy Management System", in the International Journal of Advanced Research in Electrical, Electronics and Instrumentation Engineering, ISSN 2278-8875, Vol. 8, Issue 3, March 2019.

[14] Dhanesh, L., \& Murugesan, P. (2015). Power saving of the CPU by improving the performance of the real-time system kernal using the PSCPPTS algorithm. International Journal of Applied Engineering Research, 10(5), 12465-12474.

[15] Lavanya Dhanesh, Dr.P.Murugesan (2015), "Analysing the WCET by implementing Cyclic Priority Pre- Emptive Task Scheduling algorithm" in the International Journal named "Far East Journal Of Mathematical Sciences” ISSN 0972-0871 Volume 97,Number 6, 2015 pp. 667-688. 